\title{
Tony Burton
}

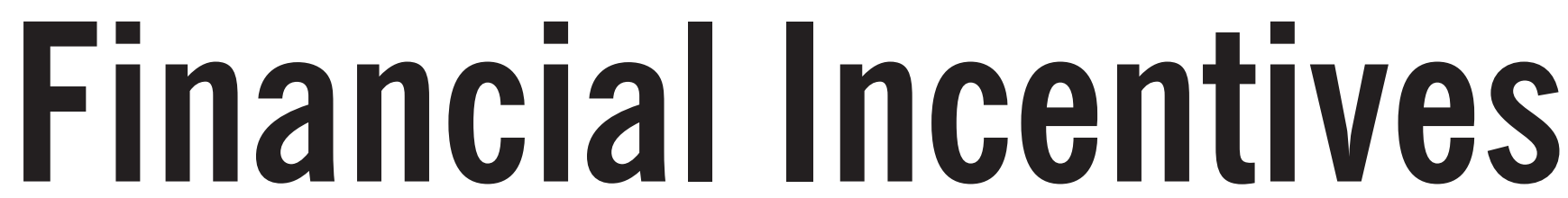

for Welfare

Recipients

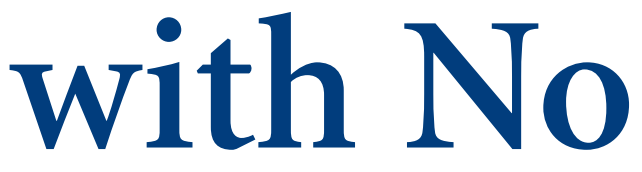

Other Income

Introduction

The Welfare Working Group final report in 2011 focused on

households whose working age members have a marginal

attachment to the labour market. The main conclusion of this

article is that a better understanding of the available options

is needed if the welfare system is to motivate people in those

households to move into paid work.

A large majority of working-age people whose main income is a welfare payment do not declare other income; thus, where the policy objective is increased

Tony Burton is a Principal Advisor in the Labour Markets and Welfare team at the New Zealand Treasury participation in paid work, the focus needs to be on motivating that participation. Policy to improve work incentives has been based on mapping bureaucratic rules, but these rules do not adequately reflect the incentives and the decision to start work. A better analysis would examine the sources of income and the uncertainty of work for people with low skills. It would also look at the incentives created by additional sources of benefit income and informal income.

This has important practical implications for policy to increase participation in paid work. Most importantly, there need to be increased resources for support to find and maintain work, and non-financial interventions which change work motivation. Financial incentives need to be targeted where they are likely to be effective, such as encouraging more than minimal participation in work.

Benefit payments and labour market participation

The great majority of people receiving a main benefit, mostly unemployment, invalid's, sickness or domestic purposes benefits, do not declare additional income. As Figure 1 shows, this has been true during recessionary and non-recessionary years. While there is variation between benefit types, more than two thirds of the recipients of each benefit have no other income each year (Ministry of Social Development, 2010, tables OB.1 and OB.2). Of those who first went onto a benefit in 1999, this was the main source of income for most of the following ten years for a third of the individuals, and for 
Figure 1: Proportion with a benefit income declaring earnings

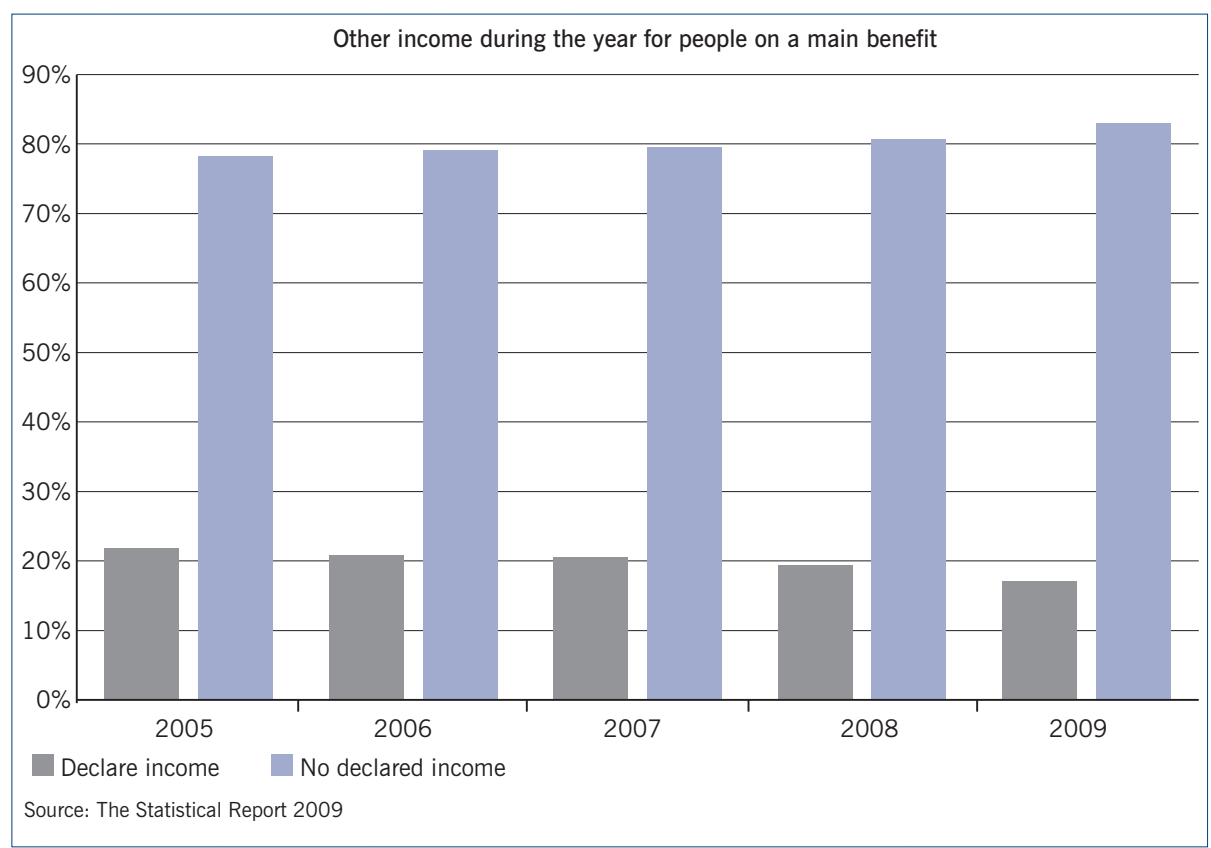

more than five of the subsequent ten years for a further third (WWG, 2010, p.10). This article discusses work incentives for these people, the substantial majority of those receiving a main benefit. This article discusses these incentives.

Before doing so, however, it is worth noting two alternative approaches which claim that participation incentives are irrelevant to policy on the labour market participation of people receiving welfare payments.

One approach argues that a person's participation in paid work is an ethical, not an incentive, issue. It emphasises the obligations created by receipt of taxpayerfunded payments and that people should support themselves wherever possible, even if they are financially worse off by doing so. In this view, a focus on the financial rewards of working provides an excuse for moral failure. A different ethical perspective focuses on income as a requirement for a decent life and draws attention to the adequacy of payments. From this perspective, giving some priority to participation incentives creates additional hardship for people already suffering great personal and financial distress through low income.

This article does not offer an ethical judgement on whether or not people should respond to financial incentives. Practical policy design is helped by understanding the reasons why people start now to have settings in place, ready for when the economy improves again.

\section{An analysis of current welfare incentives}

The economic analysis of work incentives describes the choices faced by a person deciding on a 'work/life' balance. The result is referred to as a 'budget constraint' which maps the feasible levels of time in paid work that will give the highest income. The actual balance chosen will depend on the individual and their circumstances. ${ }^{1}$ For example, a person whose only income was working 20 hours a week at $\$ 15$ an hour could not feasibly earn more than $\$ 300$ minus any taxes in that job. The budget constraint would include this and other options for doing different hours of work, subject to the cost and availability of things like child care, transport and so on. Knowing what people actually choose requires doing the empirical research.

Broadly, there are two measures of the incentive to work. One is the extra amount earned by taking up work, usually expressed as the 'replacement ratio' of unemployment income to income when in work. The other is the proportion lost of each extra dollar earned; that is, the effective marginal tax rate (EMTR). The lower both measures are, the greater the work incentive.

As noted by Prebble and Rebstock,

in considering the effects of taxes and benefits we cannot focus only on effective marginal tax rates. We must also consider the margin between the amount that can be earned in paid employment and the amount that could be received when living on a benefit. (Prebble and Rebstock, 1992, p.9)

Moreover, recent evidence suggests that:

the range of estimates reported by different studies is in fact rather similar across countries .... The bulk of this evidence indicates that ... a $1 \%$ change in the income gap between working and not working is associated with a $0.2 \%$ change in the participation rate in the same direction. (Immervoll and Pearson, 2009, p.26) 
Despite this, design of welfare policy has focused on changing EMTRs, even when there is an explicit intent to incentivise people to begin participating in the labour market. For instance, despite one of the objectives of Working for Families being to 'achieve a social assistance system that supports people into work', incentives were analysed using only the EMTR (Ministry of Social Development and Department of Inland Revenue, 2010, p.7; for other examples see Fletcher, 2011 and Department of Work and Pensions, 2010). Even worse, these analyses, including the Working for Families evaluation, are typically done by naively analysing bureaucratic tax and benefit rules, and usually only a proportion of these.

Five reasons why EMTRs do not tell us about the financial incentives on households with no earnings

For policy purposes, the question is whether or not focusing on this one measure leads to poorer policy design. This section discusses five reasons for believing that there are significant gaps in understanding incentives when using an EMTR analysis; the following section considers how policy might change with a better understanding of the incentives.

The arguments below are based on neo-classical economics to the extent they are derived from thinking that is part of that tradition; however, they are framed in terms of influences on the choice of whether or not to work, rather than 'costs of working. Partly this is to avoid discussion of what is essentially an ethical judgement about the extent of the state's obligations to subsidise work participation. But more importantly, it recognises that 'people make their decisions on the basis of their perceptions and beliefs - and these perceptions can be related in a systematic way to the parameters set by policy' (Millar et al., 1989 , p.80). Thus, the focus for policy is the people making decisions between available options, not government welfare rules.

\section{Work is not a feasible option}

The budget constraint is made up of different potential ways of balancing
Figure 2: Inverse relationship between earnings from paid work and level of benefit income

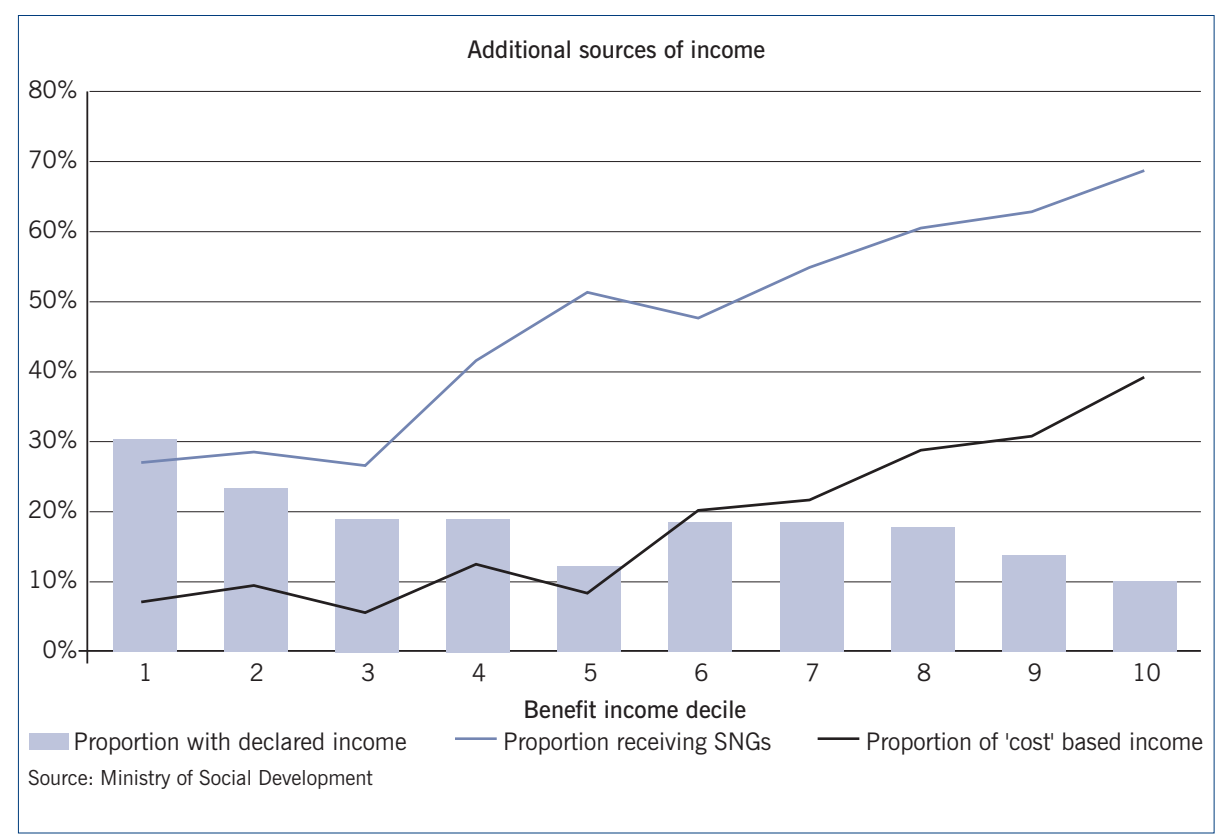

paid work and other activities. In this sense, doing no paid work is a point of balance as much as any other; but the obvious impossibility of doing less than no work qualitatively alters whether the motivation provided by financial incentives will change behaviour (Borjas, 2009, sections 2.5 and 2.6). One possibility is that a person is not working because there are no feasible job opportunities, because of, say, lack of child care, poor transport options, or lack of jobs available locally. The outcome is not the result of a lack of financial motivation to work but of a lack of real job options. Since the incentive is not the reason for doing no work, changing the incentive does not alter behaviour unless it also makes work feasible.

\section{Other activities than work are more highly valued}

Similarly, welfare payments themselves may reduce the incentive to work. Of those doing no work: around a third of those receiving the unemployment benefit, more than three quarters of domestic purposes and sickness beneficiares, and more than $90 \%$ of those on an invalid's benefit report that they are not looking for work. Indeed, the majority of people on the latter three benefits report that they do not intend to look for work for at least a year (Department of Labour, 20082010). ${ }^{2}$ The constraint is not the financial incentive, but the high value placed on having the time to do other activities. An example of this might be a sole parent whose family are willing and able to provide child care, but who does not work because he or she places a high value on looking after the children themselves. In these circumstances, altering the EMTR, even for small amounts of work, makes no practical difference to the work incentive because time spent working has not being balanced against the time spent engaged in other activities. The level of benefit income is enough that time can be spent on activities regarded as more valuable.

\section{Benefit as an alternative to paid work}

A further problem with using EMTRs is that they are developed using administrative rules that are assumed to describe the choices faced by those receiving welfare payments. ${ }^{3}$ Intuitively, it seems odd, and a little patronising, to treat the rules prescribed by an agency as a description of how people make their choices. For instance, the tax rules for schemes like KiwiSaver are designed to encourage savings, and, while these rules influence savings choices, a diagram of them does not describe why people choose to save.

An important example of bureaucratic rules poorly describing the choices for peoplem receiving welfare payments is when recipients choose between welfare 
income and earnings. For example, obtaining temporary additional support (TAS), for which a person needs to reapply every 12 weeks, requires that person to go through a process of gathering information, collating and reviewing their costs, an interview with a case manager, and other administrative tasks, all of which can take several hours' work. If the applicant is choosing between the time and difficulty involved in applying for TAS and the time and difficulty involved in work, then they are choosing between income from TAS, and income from paid work. However, a typical EMTR analysis ignores the time taken to apply for TAS and just assumes the recipient is deciding benefit income decile. However, there is still a strong relationship between income from SNGs and other sources of income, with the proportion receiving these grants decreasing as income from earnings increases. The diagram understates the effect, since those on higher benefit incomes also receive more SNGs, as well as being more likely to receive SNGs.

In fact, the New Zealand system exacerbates this problem by linking benefit income to costs over which the person receiving welfare has some control. This is the case for most supplementry benefits, including accommodation supplement, temporary additional support, disability allowance, the tax credits (which are

\section{Two key policies can be re-balanced to better use available incentives: policy to motivate welfare beneficiaries to take up paid work, and targeting financial incentives in the welfare system.}

asked about paid work, with the risks of losing any job they find frequently cited as an important reason for remaining on a benefit (Millar et al., 1989; Jenkins and Millar, 1989; Benyon and Tucker, 2006). Assessment of LEED data suggests that New Zealand is no different from other countries in this regard. Crichton and Dixon (2007) found that during 2001-02, a period of sustained economic growth, the average number of employers worked for in the two years after going off a benefit was 2.7 and the average employment spell was nine-ten months (Crichton and Dixon, 2007).

Again, this is a problem exacerbated by the way welfare payments are made. In particular, most benefits are paid after a 'stand down' period during which people are expected to use their savings to cover costs - of up to two weeks for those who have been working for longer than 26 weeks and up to 13 weeks if a person is judged to have left work voluntarily. Thus, a person thinking of coming off benefit has the strong disincentive of knowing that if they need the welfare system again - and it is reasonable to believe they will - they will have at least two weeks without income.

\section{Informal material support}

The issue of informal support that is not declared to authorities is often confused by the question of legality; yet many forms of informal support are not only legal, they are crucial in ensuring people on benefit remain engaged with society. Such support would include in-kind payments such as family meals, swapping services (hairdressing in exchange for child care, for example), gifts and so on. While these may seem of low financial value, the cost of purchasing these goods and services will be much higher than the cost of receiving them informally. Because these are often arrangements with friends and family, their non-monetary value increases the financial compensation from formal work be needed to replace them.

The key point is that informal arrangements within the domestic or civil spheres can reduce the incentives to take up paid work. It would be absurd to abate the benefit of someone who was regularly invited to meals by extended 
family, yet the cash equivalent of these arrangements might easily be more than the earnings from a day's paid work at a low wage.

\section{Some policy implications}

Incentives to take up work are only one objective of welfare systems, and welfare policy requires this to be balanced with other practical and ethical objectives. But even where the focus is these incentives, the realities of the labour market and alternative options for income mean analysing the EMTR of payment rules is inadequate for policy development.

Currently, the EMTR is adjusted so that a person receives almost $90 \%$ of the earnings for each hour of work for one day of work, and is then varied to target different levels of work for people on different benefits. For instance, the unemployment benefit rules create a disincentive for two to four days of work a week, while the combination of domestic purposes benefit and Working for Families create a disincentive for three to four days of work a week. ${ }^{4}$ A person working this number of days a week will pay $90-100 \%$ of their earnings for some of the hours they work.

Two key policies can be re-balanced to better use available incentives: policy to motivate welfare beneficiaries to take up paid work, and targeting financial incentives in the welfare system. To do this we need to take into account total additional earnings, as well as the marginal payment for each hour, because this has a greater influence on participation decisions. The discussion below also links the analysis to recommendations in the Welfare Working Group report.

\section{The enhanced role of non-financial motivation}

If manipulating payment rules has a limited influence on the motivation to take up work, then policy to increase participation needs to have a greater focus on non-financial reasons why people do not work.

First, where people are not engaging with the labour market, there need to be stronger work expectations attached to welfare payments so that far more people are motivated to take up work (WWG,
Figure 3: Improvement in income from working at the minimum wage in March $2010^{6}$

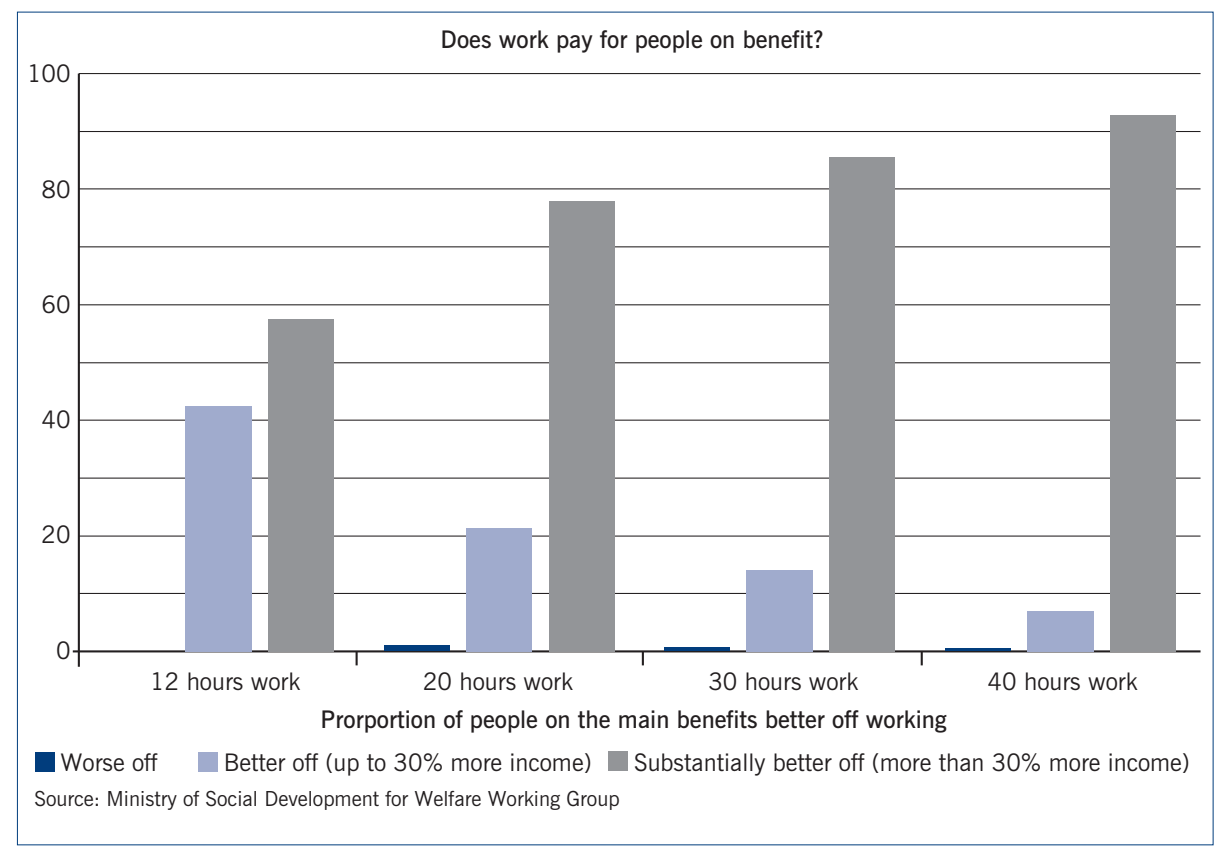

2011, p.1). The main instruments include early intervention for those with sickness and disability problems, assessment focused on capability, building stronger partnerships with the medical profession and employers, and motivating the welfare agency by making them more accountable for the financial implications of long-term welfare dependence (ibid., particularly sections 4.5, 4.6, 9.5 and 9.6).

Second, there needs to be a far greater emphasis on services to support people into work, and these services need to go to people who were not previously supported. The scale of this is such that the WWG recommended increasing by up to a third the resources to support participation in work (an increase of $\$ 285 \mathrm{~m}$ on the $\$ 770 \mathrm{~m}$ currently spent) (ibid., pp.83, 171). ${ }^{5}$ The services discussed include improved provision for sole parents, more help for people with sickness and disability, and placement services catering for those needing additional support (ibid., sections 10.4, 10.3). In addition, it was recommended that more child-care funding be targeted at people moving into work, and that more of the funding for people with disabilities be available to facilitate work (ibid., p.26, recommendations 17 and 18; pp.89-90).

Thus, the key to 'making work pay' is ensuring people have the motivation and opportunity to benefit from available work.

The use of financial incentives in the welfare system

While manipulating the EMTRs may not be effective at motivating people on welfare to start work, this is not to say people receiving welfare payments do not respond to financial incentives. If benefit payments are to be targeted at those needing income support, they have to be withdrawn when a person earns enough to support themselves. Both the payment and its withdrawal potentially create disincentives, and the question is whether policy could create more effective work incentives.

In particular, the current policy of not withdrawing payments for small amounts of work increases the rate at which they are withdrawn for higher amounts of work. Thus, to incentivise those staying on benefit to do a very small amount of work, the benefit system creates a disincentive for those wanting to work enough to potentially move out of the benefit system.

As Figure 3 shows, even at 12 hours of work more than two fifths of people on a main benefit will increase their income by less than $30 \%$. Thus, those who highly value time not working would be giving up that time for a relatively small increase in income. Even those looking for more 
income than their usual benefit will find earnings similar to their income from additional welfare payments and informal earnings. Further, the fact that such additional benefits are designed to be temporary or one-off merely replicates the uncertainty of labour market income for people on benefit. The current system targets the incentives in payment rules precisely where they are least effective.

If the aim of policy is to encourage participation in work, particularly if this is to be a step to moving off benefit, then a better use of the incentives would be to target them towards higher numbers of hours. As Figure 3 shows, substantially more people are better off when working 20-30 hours, even with the disincentives in the current system, and the financial gain is far greater than alternative sources of income. Thus, the incentive is targeted to financially reward those who have taken a major step towards replacing welfare income with earnings. This was operationalised in the WWG report by starting abatement earlier, and at a higher rate for some people, but maintaining that rate when the current system increases the rate. This is one example of a system that better aligns incentives with the objective of encouraging paid work and has the additional advantage of greater simplicity than the current system (WWG, 2011, section 5.7).

Of course, this decreases overall earnings from smaller amounts of work, and where people are unable to work longer hours would reduce hours worked.
Whether or not this means the welfare system should accept the poorer overall incentive is beyond the scope of this article. However, it should be noted that the current system reduces the earnings of people who could work two to four days a week by discouraging them from working as long as they could. Thus, whichever way the incentive is designed, some people are worse off. Further, there are ways to ameliorate the impact for those unable to work longer. For instance, the WWG report suggested identifying those whose disability or long-term illness meant they were not expected to work and removing abatement altogether for feasible amounts of work.

\section{Conclusion}

This article has argued that the incentives created by policy based on analysing EMTRs derived from bureaucratic rules do not meet the need to improve motivation to start paid work. Given that welfare rules are poor at creating incentives to participate, the argument here has been that nonfinancial motivation is more important for encouraging participation, and that financial incentives should be targeted at increasing the level of work as a step towards no longer needing welfare payments.

\footnotetext{
1 For a standard textbook treatment of labour supply decisions which includes the empirical evidence discussed below, see Borjas (2009), though any general undergraduate microeconomics textbook will have some version of the theoretical discussion.

2 Thanks to Sarah Crichton for providing this data.

3 Information on welfare and Working for Families payments can be found at http://www.workandincome.govt.nz/ manuals-and-procedures/deskfile/index.htm and http://www. workingforfamilies.govt.nz/.
}

4 For sole parents see Fletcher (2011), pp.39-41. The shape of the EMTR is broadly the same for other benefits, but they differ as to where the worse incentives start. For full details see the WINZ websites in note 3 above. One alternative is to not target the incentives and thus spread the disincentives evenly. See Rankin (1991) for a supporting view, and Treasury (2010) for an assessment. The key point for this article is that the disincentives still remain and this is just an alternative way of distributing them.

5 A substantial part of the $\$ 770 \mathrm{~m}$ is case-management time spent on administering benefit payments, so this understates the increase needed in resources to encourage participation in work.

6 Note that both the minimum wage and the level of benefit payments has increased since March 2010. Most of those worse off are on invalid's benefits.

\section{Acknowledgements}

The author would like to acknowledge his huge debt to Nick Carroll and David Rea for discussions on the topics in this article, and support provided by Margaret Dyer, Michael Fletcher, Don Gray, Doug Gorman, Paula Rebstock and Steven Sue. My thanks to Jonathan Boston and Bill Ryan at Victoria University and Simon MacPherson at Treasury for their help during its drafting. The views expressed, and any mistakes made, are the author's alone and do not reflect their views or the views of the New Zealand Treasury.

\section{References}

Benyon, P. and S. Tucker (2006) 'III health, disability, benefit and work:

a summary of recent research', Social Policy Journal of New Zealand,

29, November, pp.78-101

Borjas, G. (2009) Labor Economics, Singapore: McGraw Hill

Cowell, F. (1986) Welfare Benefits and the Economics of Takeup,

discussion paper 89, London: London School of Economics and

Political Science, Suntory and Toyota International Centres for

Economics and Related Disciplines

Crichton, S. and S. Dixon (2007) 'The longer-term employment outcomes

of people who move from a benefit to work', Social Policy Journal of

New Zealand, 31, July, pp.137-57
Department of Labour (2008-2010) New Zealand Income Survey, www. dol.govt.nz/publications/Imr

Department of Work and Pensions (2010) Universal Credit: welfare that works, London: HMSO

Fletcher, M. (2011) 'Some policy issues for reforms of assistance to sole parents', Policy Quarterly, 7 (2), pp.38-45

Immervoll, H. and M. Pearson (2009) A Good Time for Making Work Pay? Taking stock of in-work benefits and related measures across the OECD, OECD social, employment and migration working paper 81 , Paris: OECD

Jenkins, S. and J. Millar (1989) 'Income risk and income maintenance: implications for incentives to work', in A. Dilnot and I. Walker (eds), The Economics of Social Security, Oxford: Oxford University Press 
Ministry of Social Development (2002) Evaluating the February 1999

Millar, J., K. Cooke and E. McLaughlin (1989) 'The employment lottery: risk and social security benefits', Policy and Politics, 17 (1), pp.75-81

Domestic Purposes Benefit and Widows Benefit Reforms: summary of key findings, Wellington: Ministry of Social Development

Ministry of Social Development (2010) The Statistical Report 2009, Wellington: Ministry of Social Development

Ministry of Social Development and Department of Inland Revenue (2010) Changing Families' Financial Support and incentives for Working, Annex Report 1: effective marginal tax rates for Working for Families recipients, Wellington: Ministry of Social Development and Department of Inland Revenue

Moffitt, R. (1983) 'An economic model of welfare stigma', American Economic Review, 73 (5), pp.1023-35
OECD (2010) OECD Economic Outlook, 87, Paris: OECD

Prebble, M. and P. Rebstock (eds) (1992) Incentives and Labour Supply: modelling taxes and benefits, Wellington: Institute of Policy Studies

Rankin, K. (1991) The Universal Welfare State: incorporating proposals for a universal basic income, policy discussion paper 12, Department of Economics, University of Auckland

Treasury (2010) A Guaranteed Minimum Income for New Zealand: a preliminary assessment of the tax and equity implications, http://ips. ac.nz/WelfareWorkingGroup/Meetings.html

Welfare Working Group (2010) Long-term Benefit Dependency: the issues, Wellington: Institute of Policy Studies

Welfare Working Group (2011) Long-term Benefit Dependency: the recommendations, Institute of Policy Studies: Wellington

\section{Enhancing Performance- Based Regulation}

\section{Lessons from New Zealand's building control system}

\section{Peter Mumford}

Performance-based regulation establishes mandatory goals rather than enforcing prescriptive standards. Performance-based regulation has become popular over the past two decades as an alternative to prescriptive regulation, as it holds out the promise of simultaneously achieving health, safety, and environmental outcomes while facilitating innovation and reducing regulatory costs.

In the early 1990s New Zealand adopted a performance-based building control regime. This regime demonstrably failed, resulting in the 'leaky building' crisis. In Enhancing Performance-Based Regulation: Lessons from New Zealand's building control system Peter Mumford examines whether the failure can be attributed to the performance philosophy and features of the regime.

Mumford explores two strategies for resolving the challenges of decision making in a permissive performance-based regulatory environment: improving the predicative capability of decisionmaking systems through the better application of intuitive judgement associated with expertise and wisdom, and treating novel technologies as explicit experiments. Peter Mumford works for the Ministry of Economic Development. He has a broad public policy background, ranging from small and medium-sized enterprises policy and technology policy to regulatory impact analysis and regulatory policy Enhancing Performance-Based Regulation

Lessons from New Zealand's building control system

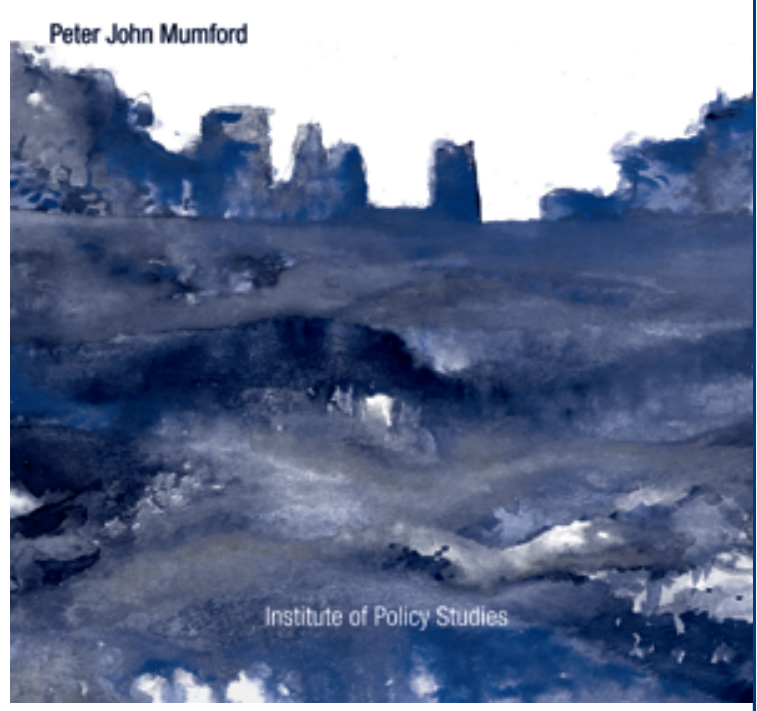

markets regulation, building controls and international regulatory coordination.

in areas as diverse as securities

An Institute of Policy Studies publication by Peter Mumford

Publication Date: April 2011

Format B5 Paperback, pp 205

ISBN ISBN 978-1-877347-43-6 - IPS/PUB/171 Price - \$27.60

(including P\&P within New Zealand)

Place your order by email, phone, fax or mail to

Institute of Policy Studies, Victoria University of Wellington

Email ips@vuw.ac.nz Telephone +6444635307

P0 Box 600, Wellington, New Zealand

An invoice will be issued with your order 